\title{
Heart rate increase and inappropriate sinus tachycardia after cryoballoon pulmonary vein isolation for atrial fibrillation
}

\author{
C. van Deutekom · B. A. Mulder (D) - H. F. Groenveld • R. G. Tieleman · A. C. P. Wiesfeld · E. S. Tan · I. C. van Gelder • \\ M. Rienstra $\cdot$ Y. Blaauw
}

Accepted: 19 August 2021 / Published online: 11 November 2021

(C) The Author(s) 2021

\begin{abstract}
Background Cryoballoon pulmonary vein isolation (PVI) is a common therapy for atrial fibrillation (AF). While moderately increased sinus rhythm heart rate (HR) after PVI has been observed, inappropriate sinus tachycardia (IST) is a rare phenomenon. We aimed to investigate the prevalence and natural history of an abnormal sinus HR response after cryoballoon PVI.

Methods We included 169/646 (26.2\%) patients with AF undergoing PVI with available Holter recordings before and 3, 6 and 12 months after the procedure. Patients with AF on Holter monitoring were excluded. Mean HR increase $\geq 20 \mathrm{bpm}$ or an IST-like pattern (mean HR $>90 \mathrm{bpm}$ or $>80 \mathrm{bpm}$ when beta-blocking agents were used) following PVI was categorised as abnormal sinus HR response.

Results Following PVI, mean $\mathrm{HR} \pm$ standard deviation increased in the entire group from $63.5 \pm 8.4$ to $69.1 \pm 9.9 \mathrm{bpm}$ at 3 months $(p<0.001)$, and to $71.9 \pm 9.4 \mathrm{bpm}$ at 6 months $(p<0.001)$. At 12 months, mean HR was $71.2 \pm 10.1 \mathrm{bpm}(p<0.001)$. Only $7 /$ 169 patients $(4.1 \%)$ met criteria for abnormal sinus HR response: mean HR was $61.9 \pm 10.6 \mathrm{bpm}$ (preablation), $84.6 \pm 9.8 \mathrm{bpm}$ (3 months), $80.1 \pm 6.5 \mathrm{bpm}$ (6 months) and $76.3 \pm 10.1 \mathrm{bpm}$ (12 months). Even at 12 months, mean HR was significantly different from that pre-ablation in this group $(p=0.033)$. However, in patients meeting IST-like pattern criteria, mean $\mathrm{HR}$ at 12 months was no longer significantly different from that pre-ablation.
\end{abstract}

C. van Deutekom • B. A. Mulder $(\bowtie) \cdot$ H. F. Groenveld • R. G. Tieleman · A. C. P. Wiesfeld · E. S. Tan · I. C. van Gelder • M. Rienstra $\cdot$ Y. Blaauw

Department of Cardiology, University Medical Centre Groningen, University of Groningen, Groningen, The Netherlands

b.a.mulder@umcg.nl
Conclusion Few patients had an abnormal sinus HR response after PVI. Peak HR was observed 3 months after PVI, but HR was still significantly increased 12 months post-ablation compared with pre-ablation. An IST-like pattern was rarely observed. In these patients, HR decreased to pre-ablation values within a year.

Keywords Atrial fibrillation - Cryoballoon - Ablation . Pulmonary vein isolation $\cdot$ Heart rate

\section{Introduction}

Atrial fibrillation (AF) is the most common sustained cardiac arrhythmia with an estimated prevalence of 33.5 million in 2010 [1]. AF is associated with a higher risk of thromboembolic events, heart failure and death

\section{What's new?}

- Previous studies have described an increased heart rate (HR) or inappropriate sinus tachycardia (IST) after pulmonary vein isolation (PVI) but have not reported long-term data on IST during follow-up.

- This is the first study to investigate the prevalence, time course and symptoms of an abnormal sinus HR response following cryoballoon PVI by combining patients with increased HR and/or an IST-like pattern.

- Abnormal sinus HR response was observed in few patients. In this group, mean HR was still significantly increased 12 months post-ablation compared with that pre-ablation. An IST-like pattern was rarely observed, and in these patients, HR normalised within a year. 
and has a significant impact on healthcare costs [2-4]. According to current guidelines, pulmonary vein isolation (PVI) can be considered as first-line treatment for patients with symptomatic AF [5]. PVI with the single-shot cryoballoon technique is a frequently used strategy [6]. It is a safe and effective procedure with known complications such as phrenic nerve palsy, access site complications, thromboembolic events and cardiac tamponade $[7,8]$.

Immediately following PVI, an increased sinus rhythm rate is observed [9-13]. In addition, during follow-up, patients may have elevated heart rates (HRs), and some fulfil criteria for inappropriate sinus tachycardia (IST) [14, 15]. Patients may experience symptoms of elevated HRs, and treatment may be troublesome.

The aim of the present study was to systematically investigate the prevalence and time course of an abnormal sinus HR response following cryoballoon AF ablation and its symptoms.

\section{Methods}

\section{Study population}

The study cohort consisted of 646 consecutive patients with AF who underwent cryoballoon PVI at the University Medical Centre Groningen between January 2013 and December 2017. Patients with missing Holter recordings pre-ablation or at 3, 6 or 12 months

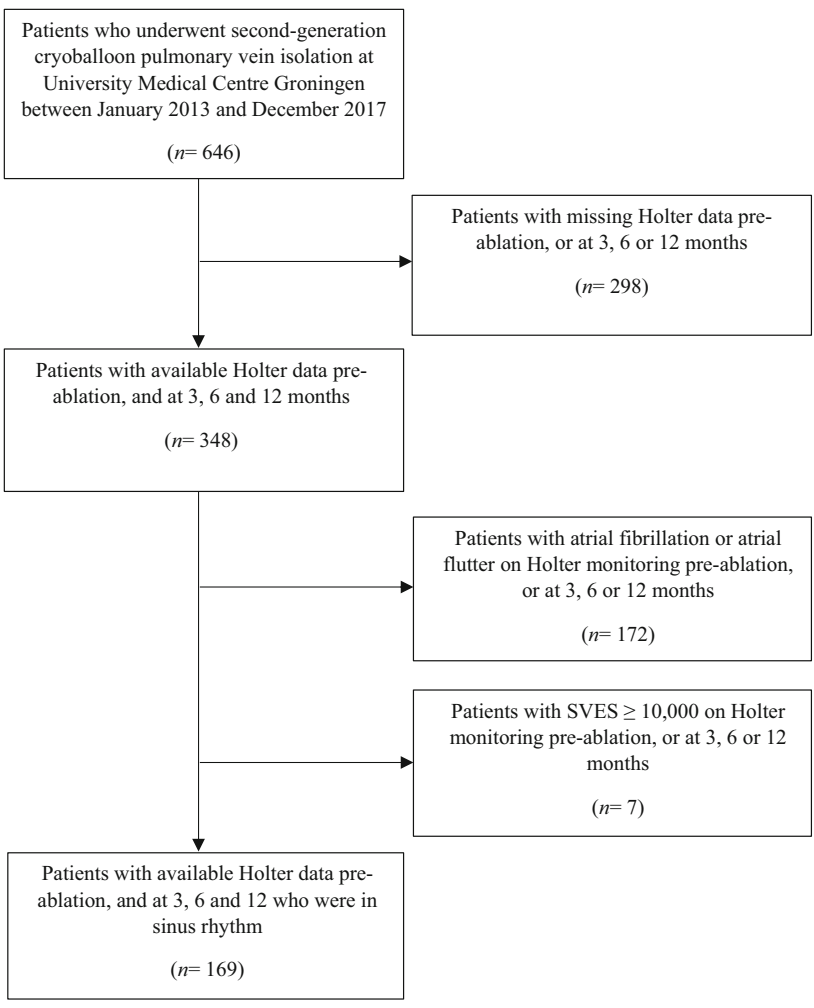

Fig. 1 Flowchart of selection process study population. SVES supraventricular extrasystole after the procedure were excluded $(n=298)$. In addition, patients with AF episodes, atrial flutter or supraventricular extrasystole $\geq 10,000$ on one or more Holter recordings were excluded $(n=179)$. The remaining 169 individuals were included for analysis (Fig. 1). All data were retrospectively collected from patients' medical files. All patients consented to the ablation procedure.

\section{Cryoballoon pulmonary vein isolation procedure}

Our cryoballoon PVI procedure has been previously described [16]. Briefly, PVI was performed under conscious sedation. From 2014 and on, the 28-mm second-generation cryoballoon (Arctic Front Advance, CryoCath, Minneapolis, MN, USA) was used for ablation. In 2017, the approach proposed by Aryana et al. was adopted [17]. The number of cryoapplications was limited to once if time to isolation was $<60$ s. A 'bonus' freeze of $120 \mathrm{~s}$ was delivered if time to isolation $<60 \mathrm{~s}$ was not observed.

\section{Clinical follow-up}

Antiarrhythmic medication was continued for the first 3 months after the procedure, after which it was discontinued in patients without symptoms of AF. Scheduled outpatient clinic visits took place 3, 6 and 12 months after the procedure. These visits were preceded by 12-lead electrocardiography and 24-hour Holter monitoring. Medical history was acquired, and physical examination was carried out during these visits.

\section{Heart rate response}

For each patient, mean 24-hour sinus HR was calculated based on Holter recordings pre-ablation and 3, 6 and 12 months after ablation. An abnormal sinus HR response was defined by combining the concepts of an increase in HR and the presence of IST-like pattern. We defined an increase in mean $\mathrm{HR} \geq 20 \mathrm{bpm}$ between the pre-ablation and the 3-month Holter recording as abnormal. We defined an IST-like pattern as a mean HR > $90 \mathrm{bpm} \mathrm{[18],} \mathrm{or} \mathrm{>} 80 \mathrm{bpm}$ if beta-blocking agents were used. A patient was labelled 'IST' if definition criteria were met at the 3-month follow-up time point and not at the pre-ablation time point in combination with an increase in mean $\mathrm{HR} \geq 10 \mathrm{bpm}$ between the pre-ablation and 3-month Holter recording. Group 1 included patients with a normal sinus HR response, and group 2 comprised patients with an abnormal sinus HR response.

\section{Outcomes}

The main objective was to evaluate the prevalence and time course of abnormal sinus HR response and the prevalence of symptoms. Incidence of abnormal sinus 
HR response as defined above was selected as primary outcome for this study. Presence of symptoms was assessed based on reports by patients in their Holter diary or from the patient chart if symptoms were noted during outpatient clinic visits.

\section{Statistical analysis}

Patient characteristics were compared between groups. Continuous variables are presented as mean \pm standard deviation and categorical variables as number (percentage). A Chi-square test was used to compare categorical variables and a $t$-test or Mann-Whitney test to compare continuous variables depending on normality of the data. For differences in mean HR pre- and post-ablation, paired $t$-tests were performed. To assess a significant difference in mean HR between groups, $t$-tests for independent samples were performed, and a one-way ANOVA was used for $>2$ groups. SPSS version 23.0 for Windows (IBM Corp,

Table 1 Patient characteristics of research population, divided into research groups

\begin{tabular}{|c|c|c|c|c|}
\hline Variable & $\begin{array}{l}\text { Total population } \\
(n=169)\end{array}$ & $\begin{array}{l}\text { Group 1 } \\
(n=162)^{\mathrm{a}}\end{array}$ & $\begin{array}{l}\text { Group 2 } \\
(n=7)^{b}\end{array}$ & $\begin{array}{l}P \text { - } \\
\text { value }\end{array}$ \\
\hline Male sex & $105(62.1)$ & $102(63.0)$ & $3(42.9)$ & 0.43 \\
\hline Age, years & $58.8 \pm 9.8$ & $59.0 \pm 9.4$ & $52.2 \pm 17.0$ & 0.33 \\
\hline $\mathrm{BMI}, \mathrm{kg} / \mathrm{m}^{2}$ & $27.5 \pm 4.7$ & $27.5 \pm 4.7$ & $25.9 \pm 4.8$ & 0.35 \\
\hline Tyре AF & & & & 0.38 \\
\hline - Paroxysmal & $137(81.1)$ & $130(80.2)$ & $7(100)$ & \\
\hline - Persistent & $30(17.8)$ & $30(18.5)$ & 0 & \\
\hline $\begin{array}{l}\text { - Long-term persis- } \\
\text { tent }\end{array}$ & $1(0.6)$ & $1(0.6)$ & 0 & \\
\hline Duration AF, days & $2041 \pm 1631$ & $2082 \pm 1643$ & $1077 \pm 946$ & 1.00 \\
\hline Bundle branch block & $11(6.5)$ & $11(6.8)$ & 0 & 1.00 \\
\hline Diabetes mellitus & $10(5.9)$ & $10(6.2)$ & 0 & 1.00 \\
\hline Hypertension & $69(40.8)$ & $68(42.0)$ & $1(14.3)$ & 0.24 \\
\hline Heart failure & $6(3.6)$ & $6(3.7)$ & 0 & 1.00 \\
\hline $\begin{array}{l}\text { Coronary artery } \\
\text { disease }\end{array}$ & $21(12.4)$ & $20(12.3)$ & $1(14.3)$ & 1.00 \\
\hline $\begin{array}{l}\text { Peripheral artery } \\
\text { disease }\end{array}$ & $8(4.7)$ & $6(3.7)$ & $2(28.6)$ & 0.04 \\
\hline LVEF, \% & $54.4 \pm 4.1$ & $54.5 \pm 4.0$ & $52.9 \pm 5.7$ & 0.24 \\
\hline LAVI, mL/m² & $33.1 \pm 9.5$ & $33.2 \pm 9.6$ & $30.0 \pm 8.4$ & 0.38 \\
\hline $\begin{array}{l}\text { Prior antiarrhythmic } \\
\text { drug use }\end{array}$ & $112(66.3)$ & $108(66.7)$ & $4(57.1)$ & 0.69 \\
\hline Flecainide use & $62(36.7)$ & $61(37.7)$ & $1(14.3)$ & 0.43 \\
\hline Sotalol use & $39(23.1)$ & $37(22.8)$ & $2(28.6)$ & 0.66 \\
\hline Amiodarone use & $18(10.7)$ & $17(10.5)$ & $1(14.3)$ & 0.55 \\
\hline \multicolumn{5}{|c|}{$\begin{array}{l}\text { Data are } n(\%) \text { or mean } \pm \text { standard deviation } \\
B M I \text { body mass index, } A F \text { atrial fibrillation, } L V E F \text { left ventricular ejection } \\
\text { fraction, } L A V I \text { left atrial volume index } \\
\text { a Group } 1 \text { comprises patients with normal heart rate }(H R) \text { response } \\
\text { b Group } 2 \text { comprises patients with abnormal sinus HR response (HR increase } \\
\geq 20 \text { bpm and/or inappropriate sinus tachycardia) }\end{array}$} \\
\hline
\end{tabular}

Chicago, IL, USA) was used to perform all statistical analyses. The significance level was set at $p<0.05$ for all statistical tests.

\section{Results}

\section{Patient characteristics}

In total, 169 patients were included for analysis (Tab. 1). Of these 169 patients, 105 (62.1\%) were male. Mean age was $58.8 \pm 9.8$ years, mean body mass index was $27.5 \pm 4.7 \mathrm{~kg} / \mathrm{m}^{2}$, and 137 patients $(81.1 \%)$ had paroxysmal AF. In total, 69 patients $(40.8 \%)$ had hypertension, 6 (3.6\%) had heart failure, and 21 (12.4\%) had coronary artery disease. Mean left ventricular ejection fraction was $54.4 \% \pm 4.1$, and 112 patients (66.3\%) were on $\geq 1$ antiarrhythmic drugs prior to PVI.

\section{Time course of mean heart rate during follow-up}

Fig. 2 shows the distribution of mean HR for the entire study population and per group pre-ablation, and at 3, 6 and 12 months post-ablation. A significant increase in mean HR was observed 3 months after ablation, and a further increase was observed at 6 months (Tab. 2). Mean HR decreased 12 months after PVI but was significantly increased compared with the pre-ablation time point (Tab. 2).

Of the 169 patients, 6 (3.6\%) met criteria for an $\mathrm{HR}$ increase $\geq 20 \mathrm{bpm}$. In this subgroup, mean HR at 12 months was significantly different from that preablation $(p=0.049)$.

Three patients $(1.8 \%)$ met criteria for an IST-like pattern. Their mean HR increased by $21.0 \pm 1.7 \mathrm{bpm}$ between the pre-ablation and the 3-month followup time points (Fig. 3). During follow-up, mean HR decreased to $80.0 \pm 8.7$ and $76.7 \pm 10.2 \mathrm{bpm}$ at 6 and 12 months, respectively. At 12 months post-ablation, mean HR was no longer significantly different from that pre-ablation.

Combining these concepts resulted in 7/169 patients $(4.1 \%)$ meeting the definition of an abnormal sinus HR response. Mean HR increased from $61.9 \pm 10.6 \mathrm{bpm}$ pre-ablation to $84.6 \pm 9.8 \mathrm{bpm} 3$ months after ablation $(p<0.001)$, after which the HR decreased to $80.1 \pm 6.5 \mathrm{bpm}$ at 6 months. At 12 months, mean HR was $76.3 \pm 10.1 \mathrm{bpm}$ and was still significantly different from that pre-ablation $(p=0.033)$. Tab. 3 shows medication use in these 7 patients during follow-up.

\section{Symptoms}

In the group with an abnormal sinus HR response, $4 / 7$ patients $(57.1 \%)$ reported symptoms, consisting of feeling an increased HR in 2 patients (28.6\%), palpitations in 2 patients $(28.6 \%)$, a restless feeling in the chest in 1 patient $(14.3 \%)$ and mild symptoms in 1 patient (14.3\%). Splitting group 2 into 'HR increase $\geq 20 \mathrm{bpm}$ ' and 'IST-like pattern', we found that $4 / 6$ pa- 
Fig. 2 Distribution of mean heart rate pre-ablation and at 3,6 and 12 months of follow-up. a Total study population. b Group 1 versus group 2

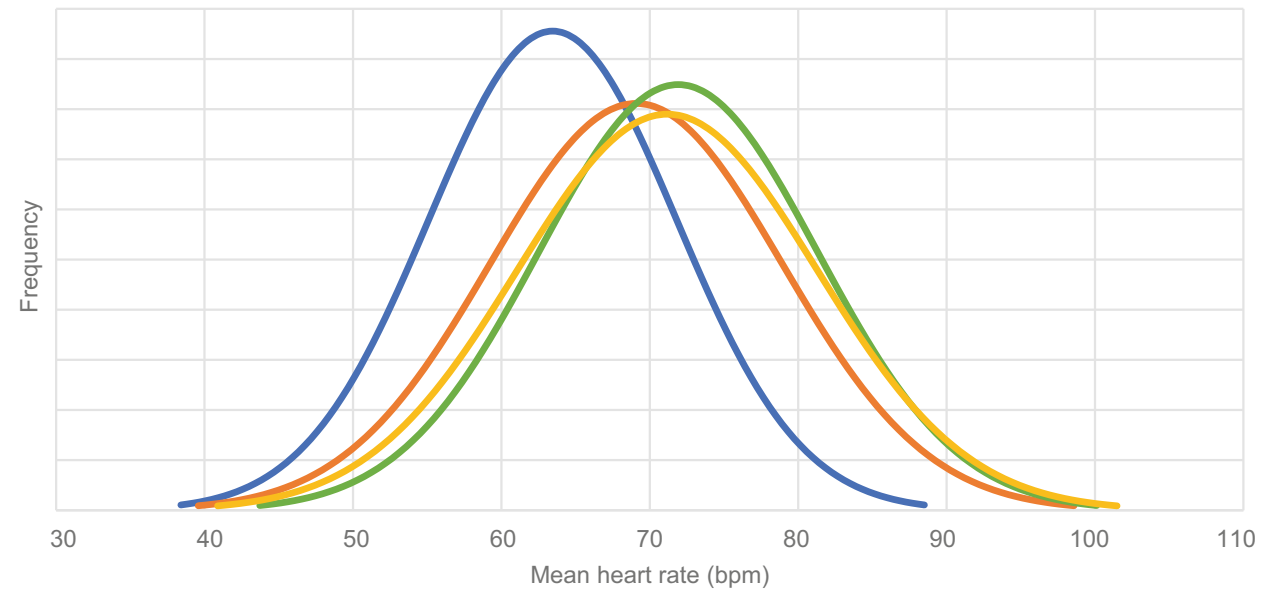
Pre-ablation -3 months $\quad 6$ months 12 months

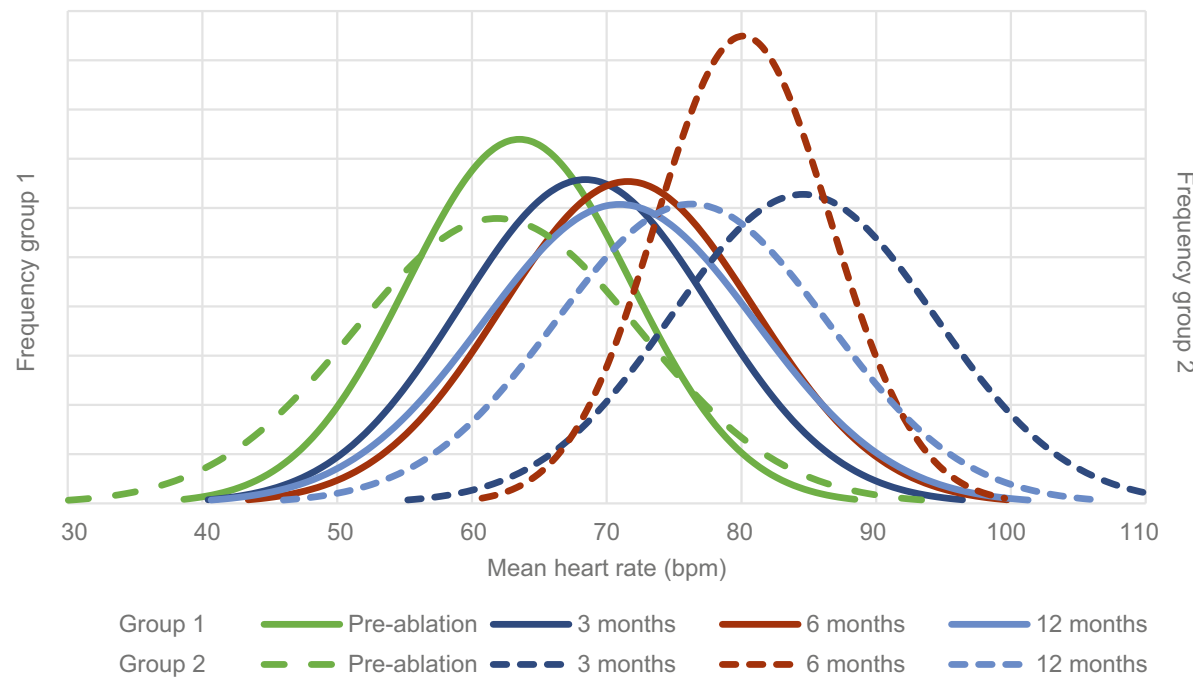

tients $(66.7 \%)$ in the group ' $H R$ increase $\geq 20 \mathrm{bpm}$ ' reported symptoms, of whom $2(33.3 \%)$ felt an increased HR, $2(33.3 \%)$ had palpitations, $1(16.6 \%)$ had a restless feeling in the chest and 1 (16.6\%) experienced mild symptoms. In the IST group, $2 / 3$ patients $(66.7 \%)$ reported symptoms, of whom $1(33.3 \%)$ felt an increased HR and 1 (33.3\%) had mild symptoms.

Two of these patients required treatment: one received bisoprolol, which reduced symptoms, and the other underwent a concealed bypass tract ablation and was symptom-free afterwards.

\section{Discussion}

The aim of this study was to determine the prevalence and time course of an abnormal sinus HR response after cryoballoon PVI. An abnormal sinus HR response was seen in $4.1 \%$ of the patients after cryoballoon ablation. One year after the procedure, this increase in

Table 2 Mean heart rate pre-ablation and during follow-up

\begin{tabular}{|c|c|c|c|c|c|c|c|c|}
\hline Group & HR response & Pre-ablation & 3 months & $P$-value & 6 months & $P$-value & 12 months & $P$-value \\
\hline Overall & & $63.5 \pm 8.4$ & $69.1 \pm 9.9$ & $<0.001$ & $71.9 \pm 9.4$ & $<0.001$ & $71.2 \pm 10.1$ & $<0.001$ \\
\hline Group $1^{\mathrm{a}}$ & & $63.5 \pm 8.3$ & $68.4 \pm 9.3$ & $<0.001$ & $71.6 \pm 9.4$ & $<0.001$ & $71.0 \pm 10.1$ & $<0.001$ \\
\hline \multirow[t]{3}{*}{ Group $2^{b}$} & Abnormal sinus HR response & $61.9 \pm 10.6$ & $84.6 \pm 9.8$ & $<0.001$ & $80.1 \pm 6.5$ & 0.007 & $76.3 \pm 10.1$ & 0.033 \\
\hline & $\mathrm{HR}$ increase $\geq 20 \mathrm{bpm}$ & $59.8 \pm 10.0$ & $83.2 \pm 9.9$ & $<0.001$ & $78.5 \pm 5.2$ & 0.017 & $75.5 \pm 10.8$ & 0.049 \\
\hline & IST & $73.0 \pm 1.0$ & $94.0 \pm 1.0$ & 0.002 & $80.0 \pm 8.7$ & 0.261 & $76.7 \pm 10.2$ & 0.604 \\
\hline
\end{tabular}


Fig. 3 Mean heart rate pre-ablation and at 3,6 and 12 months of followup per group. Significant differences in mean heart rate between groups are indicated (* compared with group 'mean $\mathrm{HR} \geq 20$ bpm'; ** compared with group 'normal response')

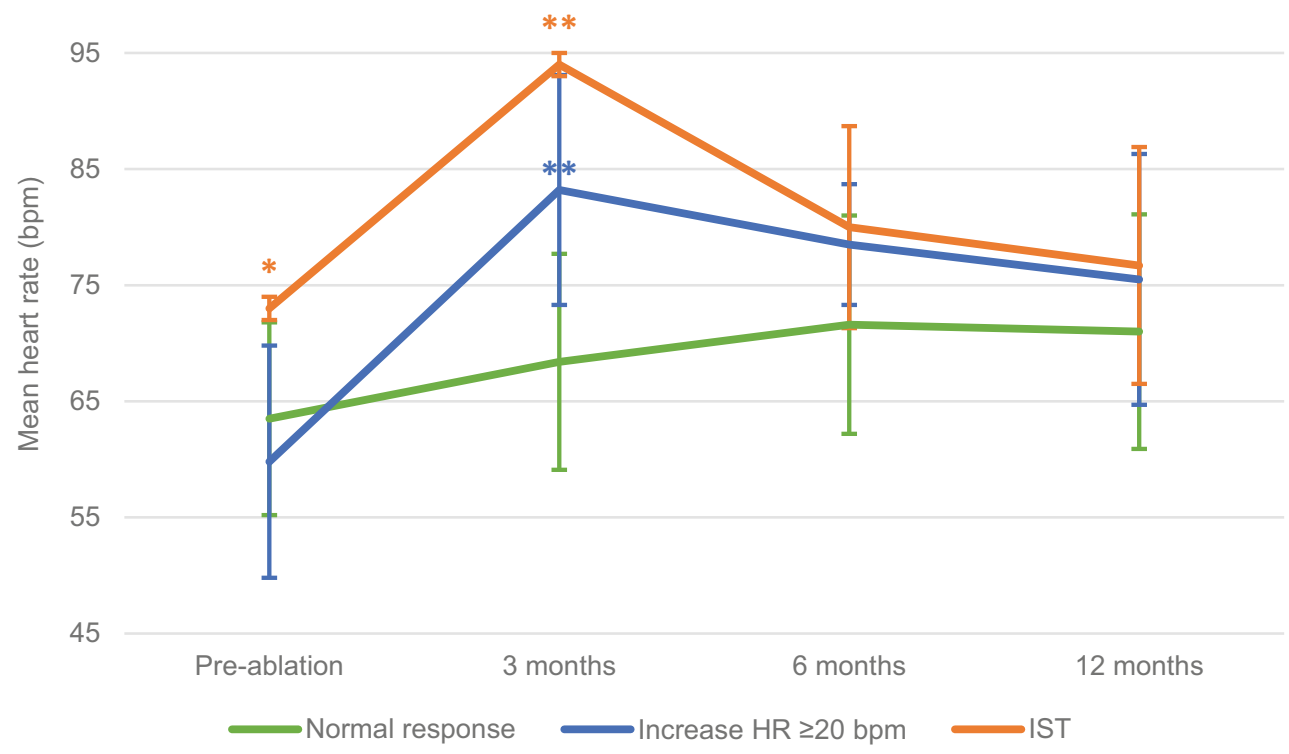

HR was still present but not in the IST-like pattern group.

In this study, we used the combination of the presence of an IST-like pattern and an increase in HR as a concept for an abnormal sinus HR response. The occurrence of IST after cryoballoon PVI has also been described by others. In a small report, one of 66 patients developed IST, with an HR of $65 \mathrm{bpm}$ pre-procedure and $100 \mathrm{bpm}$ post-procedure [14]. Comparable results were described in a case report (HR precryoballoon PVI $65 \mathrm{bpm}$, one month post-procedure $89 \mathrm{bpm}$ ) [15]. IST after PVI can occur regardless of the energy source. Pappone et al. reported on 24 patients who developed IST after radiofrequency PVI, which continued until one month after the procedure [9]. These observations are similar to the observations described in our study. However, the beforementioned papers did not report long-term data on IST or IST recovery during follow-up. Our data suggest that an IST-like pattern is rare but temporary since recovery of normal HR occurs within a year.

Table 3 Antiarrhythmic medication pre-ablation and during follow-up in abnormal sinus heart response group

\begin{tabular}{|c|c|c|c|c|}
\hline Patient & Pre-ablation & 3 months & 6 months & 12 months \\
\hline 1 & $\begin{array}{l}\text { Sotalol } 80 \mathrm{mg} \\
\text { BID }\end{array}$ & - & - & $\begin{array}{l}\text { Bisoprolol } \\
2.5 \mathrm{mg}\end{array}$ \\
\hline 2 & $\begin{array}{l}\text { Sotalol } 80 \mathrm{mg} \\
\text { BID }\end{array}$ & $\begin{array}{l}\text { Verapamil } \\
240 \mathrm{mg}\end{array}$ & $\begin{array}{l}\text { Verapamil } \\
120 \mathrm{mg}\end{array}$ & $\begin{array}{l}\text { Verapamil } \\
120 \mathrm{mg}\end{array}$ \\
\hline 3 & $\begin{array}{l}\text { Verapamil } 40 \mathrm{mg} \\
\text { TID }\end{array}$ & $\begin{array}{l}\text { Verapamil } 40 \mathrm{mg} \\
\text { BID }\end{array}$ & $\begin{array}{l}\text { Verapamil } 40 \mathrm{mg} \\
\text { BID }\end{array}$ & - \\
\hline 4 & $\begin{array}{l}\text { Sotalol } 80 \mathrm{mg} \\
\text { TID }\end{array}$ & - & - & - \\
\hline 5 & - & - & - & - \\
\hline 6 & - & - & Bisoprolol $5 \mathrm{mg}$ & $\begin{array}{l}\text { Bisoprolol } \\
5 \mathrm{mg}\end{array}$ \\
\hline 7 & $\begin{array}{l}\text { Metoprolol } \\
50 \mathrm{mg}\end{array}$ & $\begin{array}{l}\text { Metoprolol } \\
100 \mathrm{mg}\end{array}$ & $\begin{array}{l}\text { Metoprolol } \\
100 \mathrm{mg}\end{array}$ & - \\
\hline
\end{tabular}

An increase in HR after cryoballoon PVI has been previously observed as well. Sakabe et al. investigated the cardiac autonomic nervous system (CANS) after cryoballoon PVI and found a significantly increased resting $\mathrm{HR}$ in 105 patients, from $58.9 \pm 9.2$ to $72.4 \pm 9.5 \mathrm{bpm}$ [12]. Furthermore, Miyazaki et al. aimed to evaluate CANS modulation, which generally leads to an increased HR, and its effect on cryoballoon PVI outcomes [11]. They observed an increase in HR in $69.5 \%$ of the patients, which returned to pre-ablation levels 6-12 months after PVI in $31.6 \%$ but remained increased at 12 months in $37.9 \%$. They reported a mean HR increase of $18 \mathrm{bpm}$ at 3 months, comparable to the $22.7-\mathrm{bpm}$ increase in our study. There was no significant difference in patient characteristics between the groups with and without CANS modulation, which is comparable to our findings. Killu et al. included 1152 patients with radiofrequency PVI and reported a significant increase in HR, from $61 \pm 11$ to $76 \pm 13 \mathrm{bpm}$ post-ablation [19].

A possible explanation for the increase in HR is alteration of the CANS. This system consists of sympathetic, parasympathetic and sensory nerve fibres that arranged in so-called ganglionated plexi in the atrial epicardium $[20,21]$. These plexi are mainly located around the antrum of the pulmonary veins, innervating one of the four pulmonary veins and the surrounding atrial myocardium [21-23]. The function of ganglionated plexi is to modulate interactions between the extrinsic autonomic nervous system and the CANS, which allows local regulation of the sinus rate $[20,23]$. Because of their location, the major ganglionated plexi are affected by cryoballoon PVI. This treatment has been shown to elicit vagal responses, which were associated with modulation of the CANS $[11,24,25]$. This modulation resulted in reduction of parasympathetic activity, leading to an increase in HR. However, the effect may only last for 3 months after 
PVI [24]. This is in line with the peak in mean HR we saw at 3 months of follow-up.

In a study by Yu et al., 695 patients with paroxysmal AF underwent radiofrequency PVI, and 296 patients with persistent AF underwent radiofrequency PVI combined with a 'Dallas lesion' (which includes ablation of a roof line, posterior inferior line and anterior line) [26]. The authors observed a significant increase in mean HR at 3 months (from $68.8 \pm 13.1$ to $71.4 \pm 0.7 \mathrm{bpm}$ ). They defined a group with high sinus rate after ablation (mean HR $>2$ SD [ $\geq 92 \mathrm{bpm}$ ] on 24hour Holter monitoring) and found that $36 \%$ maintained this higher HR 12 months after the procedure. Furthermore, there was no significant difference in the incidence of a high sinus rate after ablation between the PVI only group and the PVI plus Dallas lesion group.

Another prognostic parameter described in the literature is heart rate variability (HRV). Pappone et al. found that time and frequency domain HRV parameters decreased after PVI [9]. There was an increase of the low-frequency/high-frequency ratio from $1.09 \pm 0.05$ pre-ablation to $1.20 \pm 0.07$ one month post-ablation. This ratio remained elevated for 3 months $(1.17 \pm 0.06)$, returning to pre-ablation levels by 6 months $(1.09 \pm 0.05)$. Sakabe et al. reported a coefficient of variation of RR interval decrease from $2.36 \% \pm 1.08$ pre-ablation to $1.24 \% \pm 0.68$ one day post-ablation $(p<0.01)$.[12] In our study, we did not have data on HRV.

What does this imply for the role of CANS in AF and consequently PVI? Abnormal CANS functioning has been shown to contribute to the development of AF [21, 27]. Different mechanisms have been proposed, one of which is vagal stimulation. Vagal stimulation reduces the refractory period, increasing the risk for re-entry of signals and thereby increasing the inducibility of AF [28]. A different mechanism is through sympathetic activation, promoting ectopic activity by affecting depolarisation [29]. In addition, simultaneous activation of parasympathetic and sympathetic fibres has also been described as a trigger for AF [30].

However, with the current techniques, it is difficult to explore the exact role of the CANS in AF development. The role of the CANS in AF development together with the observation that cryoballoon PVI is associated with modulation of the CANS (leading to an increase in HR) may explain the association of an increase in HR after PVI with AF-free survival [19].

\section{Clinical implications}

We observed a significant increase in HR after PVI. Several studies have found an association between an increase in HR and AF-free survival [10, 13, 19]. For our patients with an increased HR after PVI, this would imply a lower risk of AF recurrence compared with patients with no or a lower increase. As we only included selected patients without AF on their Holter recordings, we could not assess a relation with outcome or AF recurrence.

Additionally, our study has shown that patients may experience symptoms after PVI due to an abnormal sinus HR response, which was illustrated by continued use of medication. During outpatient clinic visits, physicians should reassure patients that these symptoms are related to the procedure and that they will subside over time. However, further exploration is needed to provide more insight into this topic.

\section{Strengths and limitations}

Strengths of this study include the large initial cohort size and the amount of Holter data available for analyses.

A limitation is that only 7 patients met criteria for abnormal sinus HR response. This may have yielded insufficient data to identify any but the largest differences. Furthermore, to investigate symptoms related to an abnormal sinus HR response, we used patients' self-reported data during Holter monitoring. These limitations complicated the ability to draw reliable conclusions on an abnormal sinus HR response and associated symptoms. An important prognostic parameter that would have been interesting to investigate, apart from mean HR, is HRV. However, data on HRV were not available for our study cohort.

\section{Conclusion}

Abnormal sinus HR response after PVI was observed in $4.1 \%$ of the patients, with a peak mean HR at 3 months. Mean HR was still significantly increased at 12 months post-ablation compared with pre-ablation, except for in patients with an IST-like pattern, in whom the HR increase was temporary.

Funding This research received no specific grant from any funding agency in the public, commercial or not-for-profit sectors.

Conflict of interest C. van Deutekom, B.A. Mulder, H.F. Groenveld, R.G. Tieleman, A.C.P. Wiesfeld, E.S. Tan, I.C. van Gelder, M. Rienstra and Y. Blaauw declare that they have no competing interests.

Open Access This article is licensed under a Creative Commons Attribution 4.0 International License, which permits use, sharing, adaptation, distribution and reproduction in any medium or format, as long as you give appropriate credit to the original author(s) and the source, provide a link to the Creative Commons licence, and indicate if changes were made. The images or other third party material in this article are included in the article's Creative Commons licence, unless indicated otherwise in a credit line to the material. If material is not included in the article's Creative Commons licence and your intended use is not permitted by statutory regulation or exceeds the permitted use, you will need to obtain permission directly from the copyright holder. To view a copy of this licence, visit http://creativecommons.org/licenses/by/4.0/. 


\section{References}

1. Chugh SS, Havmoeller R, Narayanan K, et al. Worldwide epidemiology of atrial fibrillation: a Global Burden of Disease 2010Study. Circulation. 2014;129:837-47.

2. Wolf PA, Dawber TR, Thomas HE Jr., et al. Epidemiologic assessment of chronic atrial fibrillation and risk of stroke: the Framingham study. Neurology. 1978;28:973-7.

3. Ruddox V, Sandven I, Munkhaugen J, et al. Atrial fibrillation and the risk for myocardial infarction, all-cause mortality and heart failure: a systematic review and meta-analysis. Eur J Prev Cardiol. 2017;24:1555-66.

4. Blomstrom Lundqvist C, Lip GY, Kirchhof P. What are the costs of atrial fibrillation? Europace. 2011;13(Suppl 2):ii9-12.

5. Kirchhof P, Benussi S, Kotecha D, et al. ESC Guidelines for the management of atrial fibrillation developed in collaboration withEACTS. Eur HeartJ.2016;2016:2893-962.

6. Whittaker DK. Mechanisms of tissue destruction following cryosurgery. Ann R Coll Surg Engl. 1984;66:313-8.

7. Canpolat U, Kocyigit D, Yalcin MU, et al. Long-term outcomes of pulmonary vein isolation using second-generation cryoballoon during atrial fibrillation ablation. Pacing Clin Electrophysiol. 2019;42:910-21.

8. Miyazaki S, Tada H. Complications of cryoballoon pulmonary vein isolation. Arrhythm Electrophysiol Rev. 2019;8:60-4.

9. Pappone C, Santinelli V, Manguso F, et al. Pulmonary vein denervation enhanceslong-termbenefitafter circumferential ablation for paroxysmal atrial fibrillation. Circulation. 2004;109:327-34.

10. Goff ZD, Laczay B, Yenokyan G, et al. Heart rate increase after pulmonary vein isolation predicts freedom from atrial fibrillation at 1 year. J Cardiovasc Electrophysiol. 2019;30:2818-22.

11. Miyazaki S, Nakamura H, Taniguchi H, et al. Autonomic nervous system modulation and clinical outcome after pulmonary vein isolation using the second-generation cryoballoon. JCardiovasc Electrophysiol. 2017;28:1015-20.

12. Sakabe S, Maeno K, Yamagishi H, et al. P179 Alterations of resting heart rate and heart rate viability after cryoballon ablation in the patients with paroxysmal atrial fibrillation. Eur Heart J. 2020; https://doi.org/10.1093/ehjci/ehz872. 060.

13. Maj R, Borio G, Osório TG, et al. Predictors of cardiac neuromodulation achieved by cryoballoon ablation performed in patients with atrial fibrillation who were in sinus rhythm before the ablation. IntJ Cardiol. 2020;310:86-91.

14. Guiot A, Savouré A, Godin B, et al. Collateral nervous damages after cryoballoon pulmonary vein isolation. J Cardiovasc Electrophysiol. 2012;23:346-51.

15. Sucu M, Aytemir K, Yorgun H. Innappropriate sinus tachycardia after superior vena cava isolation in addition to pulmonary veins Isolatin of paroxysmal atrial fibrillation cryoballoon ablation. J Atr Fibrillation. 2015;8:1270.

16. Mulder BA, Al-Jazairi MIH, Arends BKO, et al. Pulmonaryvein anatomy addressed by computed tomography and relation to success of second-generation cryoballoon ablation in paroxysmal atrial fibrillation. Clin Cardiol. 2019;42:438-43.

17. Aryana A, Kenigsberg DN, Kowalski M, et al. Verification of a novel atrial fibrillation cryoablation dosing algorithm guided by time-to-pulmonary vein isolation: results from the Cryo-DOSING Study (Cryoballoon-ablation DOSING based on the assessment of time-to-effect and pulmonary vein isolation guidance). Heart Rhythm. 2017;14:1319-25.

18. Brugada J, Katritsis DG, Arbelo E, et al. ESC Guidelines for the management of patients with supraventricular tachycardia The Task Force for the management of patients with supraventricular tachycardia of the European Society of Cardiology (ESC): Developed in collaboration with the Association for European Paediatric and Congenital Cardiology (AEPC). Eur Heart J. 2019;2019:655-720.

19. Killu AM, Witt CM, Sugrue AM, et al. Sinus rhythm heart rate increase after atrial fibrillation ablation is associated with lower risk of arrhythmia recurrence. Pacing Clin Electrophysiol. 2021;44:651-6.

20. Hasan W. Autonomic cardiac innervation: development and adult plasticity. Organogenesis. 2013;9:176-93.

21. Linz D, Ukena C, Mahfoud F, et al. Atrial autonomic innervation: a target for interventional antiarrhythmic therapy? JAm Coll Cardiol. 2014;63:215-24.

22. Stavrakis S, Po S. Ganglionated plexi ablation: physiology and clinical applications. Arrhythm Electrophysiol Rev. 2017;6:186-90.

23. Choi EK, Zhao Y, Everett TH, et al. Ganglionated plexi as neuromodulation targets for atrial fibrillation. J Cardiovasc Electrophysiol. 2017;28:1485-91.

24. Oswald H, Klein G, Koenig T, et al. Cryoballoon pulmonary vein isolation temporarily modulates the intrinsic cardiac autonomic nervous system. J Interv Card Electrophysiol. 2010;29:57-62.

25. Yanagisawa S, Inden Y, Mizutani Y, et al. Vagal response in cryoballoon ablation of atrial fibrillation and autonomic nervous system: Utility of epicardial adipose tissue location. J Arrhythm. 2017;33:275-82.

26. Yu HT, Kim TH, Uhm JS, et al. Prognosis of high sinus heart rate after catheter ablation for atrial fibrillation. Europace. 2017;19:1132-9.

27. Chen PS, Chen LS, Fishbein MC, etal. Role of the autonomic nervous system in atrial fibrillation: pathophysiology and therapy. Circ Res. 2014;114:1500-15.

28. Liu L, Nattel S. Differing sympathetic and vagal effects on atrial fibrillation in dogs: role of refractoriness heterogeneity. Am J Physiol. 1997;273(2 Pt2):H805-H16.

29. Qin M, Zeng C, Liu X. The cardiac autonomic nervous system: a target for modulation of atrial fibrillation. Clin Cardiol. 2019;42:644-52.

30. TanAY,ZhouS, OgawaM, etal. Neuralmechanisms of paroxysmal atrial fibrillation and paroxysmal atrial tachycardia in ambulatory canines. Circulation. 2008;118:916-25. 